\title{
Structural Analysis of a Modified Freight Wagon Bogie Frame
}

\author{
Ján Dižo ${ }^{1, *}$, Jozef Harušinec ${ }^{1}$, and Miroslav Blatnický ${ }^{1}$ \\ ${ }^{1}$ University of Žilina, Faculty of Mechanical Engineering, Department of Transport and Handling \\ Machines, Univerzitná 8215/1, 01026 Žilina, Slovak Republic
}

\begin{abstract}
This paper presents results of selected load cases for the modified freight wagon bogie frame. It comprises of two main parts. The first part is addressed to the introduction of a modified freight wagon bogie. There are described conditions for rail vehicles approval and mainly load cases which every bogie must meet for commissioning. The next part deals with computer modelling and analyses of a frame of this modified freight wagon bogie. It was analysed using the FE method and calculations were focused on the assessment of stresses of the frame structure under exceptional load. Calculation conditions were based on valid standards.
\end{abstract}

\section{Introduction}

The transport of goods by railways represents an important element of a transport service. Given than it is an environmentally friendly kind of goods transport, its importance is seen in the international and intermodal transport. Therefore, railway transport is nowadays an inseparable part of the transport system.

The rail transport in this kind of transport allows an efficient way to move large quantities of goods over longer distances [1]. Nowadays the design of rail vehicles meets conflicting requirements. On one hand there is the rail vehicles weight reducing and on the other hand all railway transport means must comply strict safety criteria. Every new designed railway vehicles and also construction units, e.g. bogies must before commissioning satisfy the terms set out in codes $[2,3]$.

\section{Description of the solved freight wagon bogie}

The largest development of freight wagon bogies design in Europe began after 1950. The main reasons for the design of new freight wagon bogie types have been constantly increasing requirements for higher speed transport and higher axle loads while reducing the risk of accidents. The effort of engineers has resulted in the design and production of the Y25 bogie [4].

This bogie is the most commonly used bogie for freight wagons mainly in the Central Europe region. The suspension of the Y25 bogie consists of a duplex coil springs with

\footnotetext{
*Corresponding author: jan.dizo@,fstroj.uniza.sk
} 
bilinear characteristic and friction dampers. The wagon body is connected with bogies by high stiffness centre pivot. The yaw movement of the bogie is damped by sidebearer pair. The friction forces between friction damper surfaces are created through the inclined Lenoir link and they are approximately proportional to the vertical load [5-7]. The Y25 bogie is most commonly designed for freight wagons running at the speed up to $100 \mathrm{~km} / \mathrm{h}$ and axle load of $22.5 \mathrm{t}$ (alt. $25 \mathrm{t}$ ) or at the speeds up to $120 \mathrm{~km} / \mathrm{h}$ and axle load of $20 \mathrm{t}$.

Since demands of the best ratio of the unloaded weight and the capacity weight of transport means are constantly required, engineers try to modify their design within their capabilities and maintaining its all positive operational properties and reliability [8-10]. Developers of rail vehicles have therefore come to the possibility to modify a frame of the original Y25 bogie by removing buffer beams $[11,13]$. Such a frame is lighter, which is beneficial for the capacity weight increasing. Figure 1 shows design of the original and the modified freight wagon bogie [13].
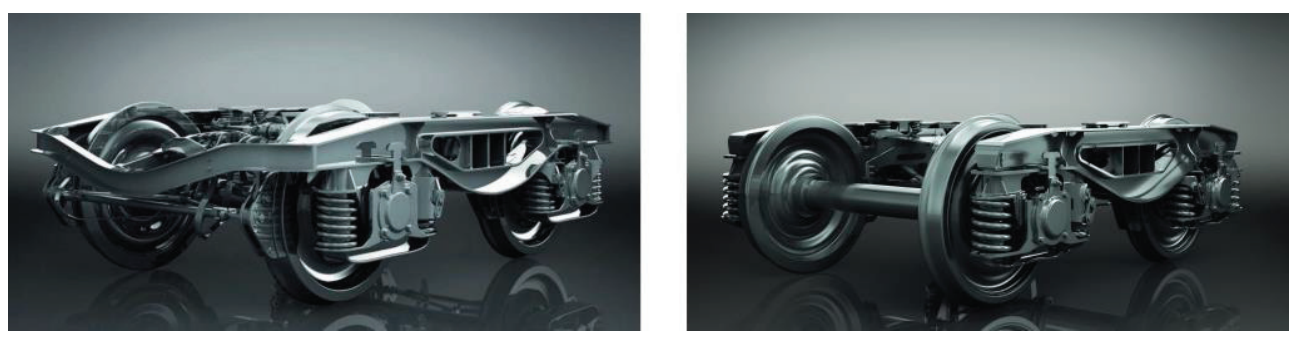

Fig. 1. Design of the original (left) and modified (right) freight wagon bogie. Source: [13]

If we compare the unloaded weight of the original bogie and the modified bogie with comparable equipment (brake type, bogie determination, etc.) we can find out that one bogie saves approx. $250 \mathrm{~kg}$ [13] and since standard wagons (i.e. the most often used wagons with Y 25 bogies) are usually equipped with two such bogies, the wagon weight is no longer negligible.

From the operation point of view reducing the wagon unloaded weight means increasing the wagon capacity weight, lower operating costs when a wagon is transported in an unloaded state by saving energy consumption [14] and from the production point of view we can save material costs and partly to reduce needed production time.

Nevertheless every intervention in the load-bearing construction requires a through strength calculations supported by experimental measurements on test benches $[15,16]$. The bogie frame is the main carrying part of the bogie. Therefore it is not possible to perform such the essential modification of the frame without adequate analyses $[17,18]$. They come out and rely on strict requirements embedded in relevant standards and regulations.

In European standard EN 13749 the considered analysed bogie is classified in the category B-V: bogies freight rolling stock with single-stage suspensions $[2,19]$.

In the next part of the article, the requirements for wagon bogie as well as the results of the strength calculations and analyses of the modified bogie frame for chosen load cases are presented.

\section{Rail vehicle bogies loads}

A real bogie and its frame are loaded in real operational conditions by a wide spectrum of a load which depends on actual level of loading, quality of a track expressed by variations form its geometric ideal position load or an eventual buckling of the track in the given track section and various others factors. These result in the variable operational load which is 
practically not possible to describe by load dependencies. Therefore for the load of bogie frames the replacement load spectrum was determined according to which new developed bogies are tested [20]. For this testing load bogie frames are designed and optimised in terms of strength and virtual testes. This testing load is intended in legislation, such as UIC edict, European and national norms or internal directives of a vehicle operator [2, 3, 19]. In this contribution the bogie frame is tested using virtual models while the calculation conditions are based on the European standard, in which requirements on bogie frame are defined.

Generally, various load cases of bogies frames can be divided into external and internal. load:

For all categories in all applications the internal load is defined as well as the external

- Exceptional load, which should not produce permanent deformation or excessive deflections.

- Normal service loads, which should not induce fatigue cracks.

European standard regulates the calculation of an internal load of bogies by accelerations determination, which the appropriate component must withstand without defects or loss of function.

\subsection{Combinations of individual loads of bogie}

Loads defined above are in reality not individual, but they act concurrently in various combinations and in various intensity. For needs of the strength and dynamic design of a bogie frame the European standards submit several selected load combinations.

They are compiled to meet the bogie frame design to withstand possible combined operational loads.

In the European standard two combinations of a load are defined static load combination and dynamic load combination.

Prescribed loads combinations represent the base not for design and optimisation of bogie frames but also subject for verification tests on test benches. They are distinguished static and dynamic load cases.

Bogie structures are loaded by a very high number of dynamic load of a variable size. Effects of such load are concentrated in critical locations of a bogie frame (e.g. points of action forces, geometry changes, welded joints etc.). The objective of fatigue tests is verification, if a bogie frame has a sufficient fatigue strength, i.e. if a cyclic operational load does not result to initiation of fatigue cracks or fractures. Fatigue stresses is possible to determine by two methods, i.e. fatigue resistance, if the fatigue lifetime is known (stress value, in which under load by determined number of cycles the fatigue damage not occur) and cumulative damage, if the stress is constantly under of the fatigue lifetime level for all determined load combinations.

In our work we have considered only the static load combination.

\section{Computer analysis of the bogie frame}

Ride properties significantly influence on rail vehicles mechanical systems dynamic behaviour [21]. We can theoretically predict the movement of the wheelset on a track by means of the wheelset and track geometric characteristics analysis [22]. Geometric characteristics define the rail/wheel profiles contact couple geometrical relationship. The shape of the contact couple crucial influences the size of the contact patch and contact stress between wheel and rail value [23]. This creates loading and excitation forces acting inside vehicle and track systems [24]. The analysis of the mechanical systems dynamics may be analysed using various methods $[25,26]$. 
The analysed frame is component of a freight wagon bogie. According to standard this bogie belongs the category B-V namely Freight bogies with a central pivot and two sidebearers $[2,19]$. We have analysed this bogie frame in such way that we proceeded in accordance with a valid standard.

In boundary conditions and loads definition of the bogie frame we have come out of the standards.

\subsection{Bogie frame load definition}

The total weight of the bogie was $m=5.0 \mathrm{t}$, wheelbase $b=1.8 \mathrm{~m}$. The bogie is determined for a freight wagon with the total weight of $M_{W}=90 \mathrm{t}$.

The bogie is loaded in the vertical direction by the force:

$$
F_{Y}=\left(\frac{M_{W}}{2}-m\right) \cdot g
$$

For the vertical direction the value of the exceptional load is given by these formulas:

- if vertical forces act only in the centre pivot:

$$
F_{Y P \max }=2 \cdot F_{Y}
$$

- if vertical forces act in the centre pivot and on the one sidebearer:

$$
\begin{gathered}
F_{Y 1 \max }\left(\text { or } F_{Y 2 \max }\right)=1.5 \cdot F_{Y} \cdot \alpha \\
F_{Y P}=1.5 \cdot F_{Y}(1-\alpha)
\end{gathered}
$$

where $F_{Y}$ is the total vertical load the a bogie, $F_{Y P}$ is the vertical force acts in the centre pivot, $F_{Y 1}$ and $F_{Y 2}$ are vertical forces act on sidebearers, $\alpha$ is coefficient for the body swinging. In our case we have considered with the value of $\alpha=0.3$.

For the lateral force of the exceptional load acting on the every wheelset there is applied following:

$$
F_{Z 1 \max }=F_{Z 2 \max }=\frac{F_{Z \max }}{2}=10^{4}+\frac{F_{Y}+m \cdot g}{6}
$$

The longitudinal force straining bogie frame is given:

$$
F_{X 1 \max }=0.1 \cdot\left(F_{Y}+m \cdot g\right)
$$

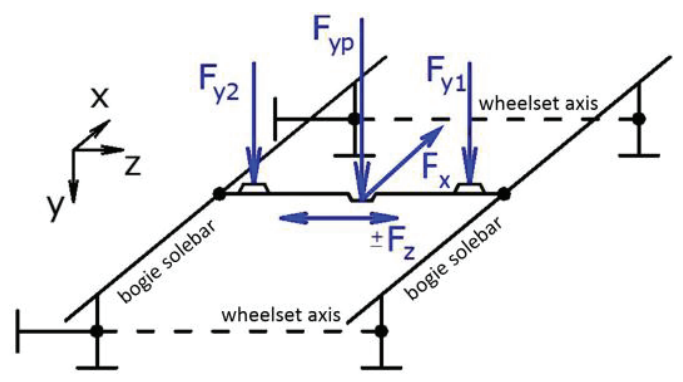

Fig. 2. Scheme of load point applications. Source: [2, 19]

The load involved in case of the wagon impact is possible to substitute for the static longitudinal force acting in places, where the equipment is connected to the bogie. Its value is determined from the mass of individual elements and maximum acceleration acting on them during wagon impact [19]. 


\subsection{Calculations and results}

For strength analyses using FEM we have used Ansys software. It allows engineers to create computer models of structures, machine components or whole systems, apply operating load and other design criteria and study physical responses $[27,28]$, such as stress levels, pressure, deformations, etc.

Process of the bogie frame computer analysis includes several steps, which are needed to perform for successful calculation. We can it describe as follows:

- Creation of a CAD model of the considered body, appropriate model files generation.

- Setting up a FEM model in Ansys.

- Model - generation of 8-nodes shell elements and 10-nodes quadratic tetrahedron elements (axle guides and centre pivot).

The bogie frame is generally made of combination S235 and S355 steels, which minimal yield stress is 340 - $440 \mathrm{MPa}$ and $520-630 \mathrm{MPa}$, respectively. The S355 steel is used for the centre pivot and axle guides. Therefore, we have defined these parameters of material model:

- Material was considered homogenous, isotropic, linear and elastic.

- Mechanical properties - Young's modulus of elasticity $E=2.1 \cdot 10^{11} \mathrm{~Pa}$, Poisson's ratio $\mu=0.3$.

Next there are presented results from computer analyses of the modified bogie frame, which was subjected to four load cases corresponded to the exceptional load described in chapter 4.1 .

Table 1 contains calculated data, which are needed to apply as loads on the bogie. The third column indicates, which formula from chapter 4.1 was used for calculation.

Table 1. Calculated loads for bogie frame. Source: authors

\begin{tabular}{|c|c|c|}
\hline Load & Calculated value [kN] & Formula \\
\hline $\boldsymbol{F}_{\boldsymbol{Y}}$ & 392.4 & $(1)$ \\
\hline $\boldsymbol{F}_{\boldsymbol{Y} \max }$ & 784.8 & $(2)$ \\
\hline $\boldsymbol{F}_{\boldsymbol{Y} \max }$ & 176.58 & $(3)$ \\
\hline $\boldsymbol{F}_{\boldsymbol{Y} \boldsymbol{P}}$ & 412.02 & $(4)$ \\
\hline $\boldsymbol{F}_{\boldsymbol{Z} \text { max }}$ & 83.575 & $(5)$ \\
\hline $\boldsymbol{F}_{\boldsymbol{X} \text { max }}$ & 44.145 & $(6)$ \\
\hline
\end{tabular}

As mentioned above, in this work we have focused on four most unfavourable load combination cases. These load combinations are embedded in the described standard. They practically represent combinations of calculated loads from Table 1 and Figure 2 shows points of application and directions of individual loads.

Load combinations are listed in Table 2.

Table 2. Calculated load combinations. Source: authors

\begin{tabular}{|c|c|c|c|c|c|}
\hline Load case & $\boldsymbol{F}_{\boldsymbol{Y} \boldsymbol{\operatorname { m a x }}}[\mathrm{kN}]$ & $\boldsymbol{F}_{\boldsymbol{Y} \boldsymbol{P}}[\mathrm{kN}]$ & $\boldsymbol{F}_{\boldsymbol{Y} \max }[\mathrm{kN}]$ & $\boldsymbol{F}_{\boldsymbol{Z} \text { max }}[\mathrm{kN}]$ & $\boldsymbol{F}_{\boldsymbol{X} \max }[\mathrm{kN}]$ \\
\hline $1^{\text {st }}$ & 784.8 & 0 & 0 & 0 & 0 \\
\hline $2^{\text {nd }}$ & 0 & 412.02 & 176.58 & 0 & 0 \\
\hline $3^{\text {rd }}$ & 0 & 412.02 & 176.58 & 83.575 & 0 \\
\hline $4^{\text {th }}$ & 0 & 412.02 & 176.58 & 0 & 44.145 \\
\hline
\end{tabular}

Figure 3 shows results from strength numerical analyses of the modified freight wagon bogie frame under four load cases according to the table. We have evaluated stresses according to the HMH hypothesis.

The frame structure is satisfactory, if in all load cases evaluated stresses are less than the yield stress of the used material. 
Let's look at Fig. 3. The first load case is the state when the highest value of the exceptional load acts on the frame $\left(F_{Y P \max }=784.8 \mathrm{kN}\right)$, but only in the centre pivot. Under influence of this load the highest values of the stress arise in the centre pivot region. The maximum is $460.71 \mathrm{MPa}$. This would indicate, that the frame structure in this region is at the limit of acceptability. But we have to consider important facts.

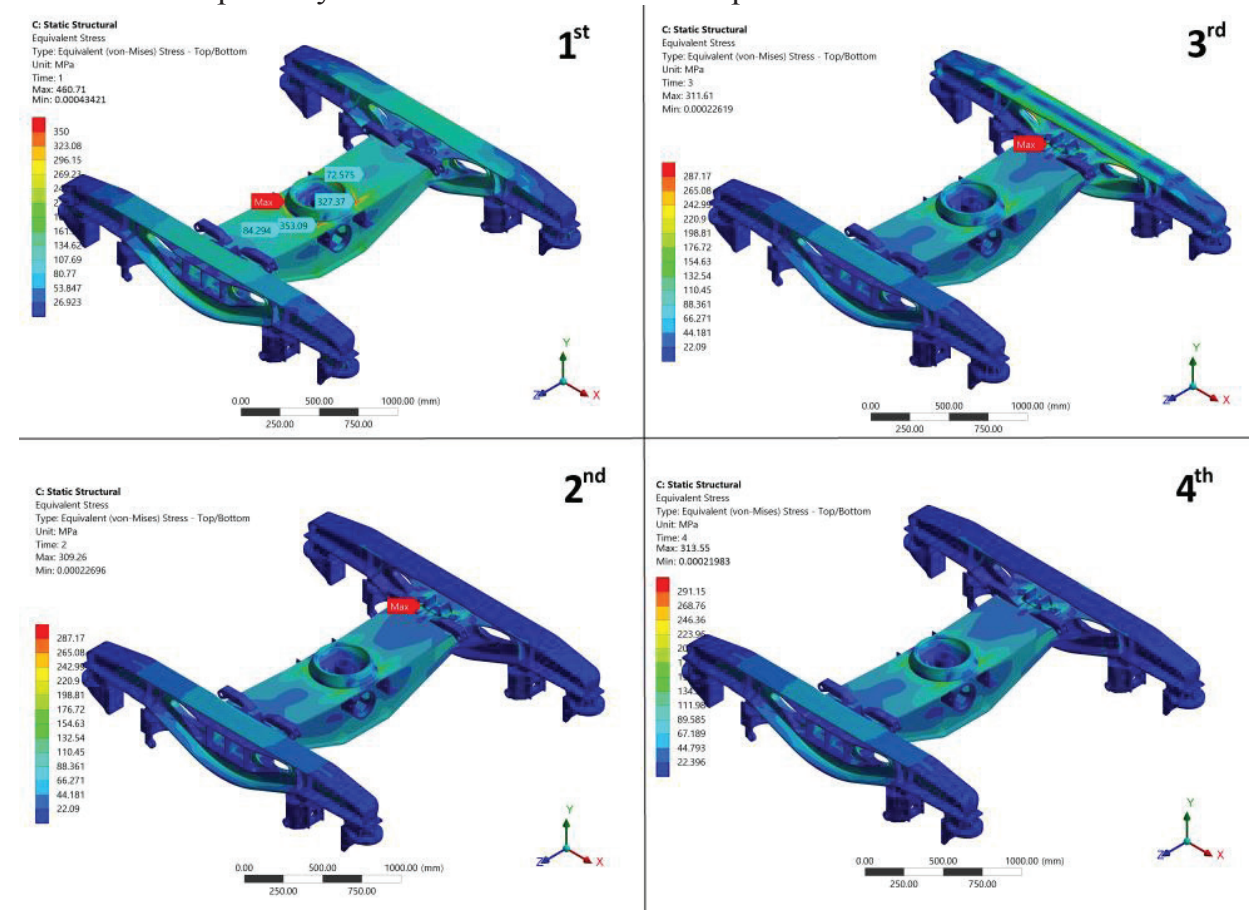

Fig. 3. Results of strength analyses. Source: authors

The centre pivot is made of steel with the higher yield stress, therefore for this part the minimal yield stress value of $520 \mathrm{MPa}$ is valid. Moreover during calculations more variants of FE mesh size were used and compared. Based on results we have found out that this extreme value is obviously caused by calculation errors. Other values are lower and comply given limits (see Fig. $3,1^{\text {st }}$ ).

In the second exceptional load case the frame was loaded by forces acting in the centre pivot and on the one sidebearer (namely $F_{Y P}=412.02 \mathrm{kN}, F_{Y I \max }=176.58 \mathrm{kN}$ ). This load simulates the body swinging. From results we can see (Fig. $3,2^{\text {nd }}$ ), that the maximum stress is in the loaded sidebearer area and it reaches value of 309.26 MPa. It is even safely below the yield stress of the S235 steel.

In the third load case the exceptional load is formed in addition to vertical forces $\left(F_{Y P}=412.02 \mathrm{kN}, F_{Y I \max }=176.58 \mathrm{kN}\right)$ also by the lateral force $\left(F_{Z I \max }=83.575 \mathrm{kN}\right)$. As we can see in Fig. 2, two forces act in the centre pivot and one loads frame on the sidebearer. The maximum stress is again in the loaded sidebearer area (Fig. $3,3^{\text {rd }}$ ). The value of 311.61 MPa is higher than in the previous load case, but still within permitted limits.

Finally, let's move to the fourth load case. When we compare this case with the previous one, we can notice, the vertical load is the same $\left(F_{Y P}=412.02 \mathrm{kN}\right.$, $\left.F_{Y I \max }=176.58 \mathrm{kN}\right)$, but the horizontal force acts in the longitudinal direction $\left(F_{X I \max }=44.145 \mathrm{kN}\right)$. This force simulates the frame load resulting from a running wagon dynamics. The calculated maximum stress value (Fig. $3,4^{\text {th }}$ ) is slightly higher in comparison with the third load case and that is $313.55 \mathrm{MPa}$. It is still well below the yield stress. 
In the future, we will research mechanical properties and dynamic behaviour of an entire modified bogie. We will create a mechanical system of a modified bogie in a multibody software and our just analysed FE model will serve as an important input for setting up a multibody system with a flexible body in order to study its dynamic properties and to compare with the original bogie for the detection of possible problems in terms of long-term operation $[29,30]$.

\section{Conclusion}

To summarising, we have created the three-dimensional model of a modified freight wagon bogie frame. Because it is a fairly new design of a freight wagon bogie, we wanted to know, if this new frame structure is able to meet strict criteria for all new designed rail vehicles and their components, mainly bogies. From all scale of load cases we have chosen four cases included as exceptional loads. We have performed numerical analyses of the bogie frame structure and based on results we have found out that the structure meets requirements prescribed in the standard. For making clear conclusions it would be necessary to compare results from numerical calculations and measurements to each other. This is the intention of further research in this area.

This article was supported by the project VEGA 1/0927/15 "Research of the use of alternative fuels and hybrid drives on traction vehicles with aim to reduce fuel consumption and air pollutants production".

The work was supported by the Cultural and Educational Grant Agency of the Ministry of Education of the Slovak Republic in project No. KEGA 077ŽU-4/2017: Modernization of the Vehicles and engines study program.

This publication is the result of the project implementation: Modern methods of teaching control and diagnostic systems of engine vehicles ITMS 26110230107 supported by the Operational Programme Education funded by the ESF.

\section{$\checkmark$ VÝSKUMNÁ}

\section{*** Európska únia \\ Štrukturálne fondy}

This paper is supported by the research project "From horse-drawn railway to intermodal transport" within Visegrad Fund.

\section{References}

1. M. Kendra, M. Babin, D. Barta, Transport Research Arena 2012 48, 743-752 (2012), DOI: 10.1016/j.sbspro.2012.06.1052

2. EN 13749, Railway Applications - Wheelsets and bogies - Method of specifying the structural requirements of bogie frames, European Committee for Standardization (Brussels, Belgium, 2011)

3. UIC 566, Loading of coaches bodies and their components (1994)

4. J. Dižo, J. Harušinec, M. Blatnický, Soucasne problemy v kolejovych vozidlech, 29-36 (2017)

5. J. Gerlici, T. Lack, Soucasne problemy v kolejovych vozidlech, 117-125 (2017)

6. T. Lack, J. Gerlici, Y25 freight car bogie models properties analysis by means of simulation computations (to be published)

7. M. Maňurová, A. Suchánek, Manufacturing Technology 16, 390-396 (2016) 
8. O. Lunys, S. Dailydka, S. Steišunas, G. Bureika, Procedia Engineering 134, 64-71 (2016), DOI : 10.1016/j.proeng.2016.01.040

9. J. Gerlici, O. Nozhenko, G. Chernyak, T. Lack, M. Gorbunov, R. Domin, The development of diagnostics methodological principles of the railway rolling stock on the basis of the analysis of dynamic vibration processes of the rail (to be published)

10. J. Grenčík, R. Poprocký, P. Volna, J. Galliková, Use of risk assessment methods in maintenance for a more reliable rolling stock operation. (to be published)

11. P. Štastniak, L. Smetanka, M. Moravčík, Manufacturing Technology 17, 250-256 (2017)

12. J. Gerlici, M. Gorbunov, O. Nozhenko, T. Lack, S. Kara, K. Kravchenko, Soucasne problemy v kolejovych vozidlech, 109-116 (2017)

13. Tatravagónka Inc., Products, Bogies (2017)

14. L. Kašiar, P. Zvolenský, D. Barta, L. Bavlna, M. Mikolajčík, P. Drożdziel, Diagnostyka 17, 3, 95-101 (2016)

15. J. Gerlici, T. Lack, J. Harušinec, Applied mechanics and materials 486, 387-395 (2014), DOI: 10.4028/www.scientific.net/AMM.486.387

16. J. Gerlici, T. Lack, Applied mechanics and materials 486, 379-386 (2014), DOI : 10.4028/www.scientific.net/AMM.486.379man

17. V. Hauser, O. Nozhenko, K. Kravchenko, M. Loulová, J. Gerlici, T. Lack, Car body and bogie connection modification for track curves passability improvement (to be published)

18. V. Hauser, O. Nozhenko, K. Kravchenko, M. Loulová, J. Gerlici, T. Lack, Innovative wheel tread design aimed to tramcar-track interaction improvement when passing curves of a small radius (to be published)

19. D. Kalinčák, Rail vehicles I (In Slovak) (University of Žilina, Faculty of Mechanical Engineering, Slovak Republic, 2008)

20. R. Mełnik, M. Kostrzewski, Structural Health Monitoring II 518, 281-288 (2012), DOI : 10.4028/www.scientific.net/KEM.518.281

21. J. Gerlici, T. Lack, Applied mechanics and materials 486, 396-405 (2014), DOI: 10.4028/www.scientific.net/AMM.486.396

22. J. Gerlici, T. Lack, Wear 271(1-2), 246-258 (2011), DOI: 10.1016/j.wear.2010.10.052

23. J. Gerlici, M. Gorbunov, K. Kravchenko, O. Prosvirova, T. Lack, Noise and temperature reduction in the contact of tribological elements during braking (to be published)

24. M. Maňurová, A. Suchánek, Manufacturing Technology 16, 1020-1027 (2016)

25. P. Hejma, M. Svoboda, J. Kampo, J. Soukup, Procedia Engineering 177, 3-10 (2017), DOI: 10.1016/j.proeng.2017.02.175

26. P. Baran, M. Brezáni, P. Kukuča, P. Št’astniak, Procedia Engineering 192, 34-39 (2017), DOI: 10.1016/j.proeng.2017.06.006

27. F. Klimenda, J. Soukup, Procedia Engineering 177, 11-16 (2017), DOI: 10.1016/j.proeng.2017.02.176

28. J. Soukup, B. Skočilasová, J. Skočilas, Vibration of the steel frame of the primary sand classifier (to be published)

29. J. Dižo, J. Harušinec, M. Blatnický, Manufacturing Technology 15, 781-788 (2015)

30. M. Kostrzewski, R. Mełnik, Procedia Engineering 192, 439-444 (2017), DOI: 10.1016/j.proeng.2017.06.076 